\title{
Performance Analysis and Comparison of Symmetrical and Asymmetrical Dual Stator Induction Generators for Wind Energy Conversion Systems
}

\author{
Ramesh Singh \\ Department of Electrical Engineering \\ Delhi Technological University \\ Delhi, India
}

\author{
Vishal Verma \\ Department of Electrical Engineering \\ Delhi Technological University \\ Delhi, India
}

\begin{abstract}
The emergence of micro/nano level wind generation has opened the research on induction generator (IG) topologies having easier and finer control available in multiphase generators. To establish the suitability of multiphase generators for wind generators the analysis of their performance based on the developed model for the same rating of six phase symmetrical $\left(60^{\circ}\right)$ and asymmetrical $\left(30^{\circ}\right)$ IGs is presented. A comparative performance evaluation of grid-excited six phase symmetrical and asymmetrical IGs also known as Dual Stator Induction Generators (DSIGs) is presented through simulation results in MATLAB/SIMULINK environment amidst load perturbations, limited variation of wind speed and perturbations in voltage and frequency of the non stiff micro-grid to which they are connected. Based on the performance indices like flux of direct and quadrature axis, speed variations, terminal voltage drop/rise, range of operational speed variation etc., a comparative analysis with the help of the results is drawn to establish the suitability of asymmetrical multiphase IGs for grid connected wind generators.
\end{abstract}

Keywords-dual stator induction generator; wind energy conversion system

\section{INTRODUCTION}

Recent advances and research in the field of power electronics has changed the scenario of power generation from large scale generation to distributed micro, nano and pico generation. Due to their suitability for power generating at variable speed and having rugged brushless structure with maintenance, free operation squirrel cage induction generators (SCIGs) are fast finding place for wind generation. The specific requirements for grid connected generator coupled with wind turbines include better regulation of terminal voltage, better stability, uniform distribution of flux, higher electrical inertia to meet the transients, higher efficiency and cost effectiveness and better low voltage ride through (LVRT) capability. Normally multistage gear train/single stage plenary gear train is employed for coupling SCIG to enable its working in a wide range of speed variation, but larger gear ratio and multistage gear train reduces efficiency to a great extent by incurring losses [1]. Reported literature reveals that full rated back to back voltage source converter (BTB-VSC) may be employed to harvest energy in higher speed range by vector or scalar control of IG side VSC [2]. Such topologies increase the cost of the system as full power passes through the DC link. To overcome such issues DFIGs were introduced where direct grid connection of stator winding was possible for operation amidst large variation of wind speed [2]. Such configuration removes the dependency on gear train thus becomes more efficient and cost effective for large power range [3]. Employing wound rotor induction machine increases the machine cost and requires regular maintenance [3]. Moreover the LVRT capability of DFIG is also very poor [4]. To offset the increased cost and LVRT capability such machines are well suited for coupling with big wind turbines [4]. To make the suitability of DFIG regarding free structure maintenance i.e. getting rid of slip-rings and IG with better LVRT brushless doubly fed induction generator (BDFIG) which has two stator windings with one nested loops rotor winding is reported in literature [5]. BDFIGs have demonstrated better LVRT capability and have shown their suitability to work with variable speed operation [5]. The increased cost of BDFIGs like DFIG leaves the scope for furthering in research with multi stator IGs for wind energy applications. Other reported topology included split phase induction generators (SPIGs) where there are two stator windings with squirrel cage rotor but the poles of both stators are different. Sharing of power between them is made via rotor, making transient response slower and incurring considerable losses [5-7].

Dual stator induction generators (DSIGs) have emerged as suitable alternative to both DFIGs and BDFIGs where the two stator windings are used with squirrel cage rotor, and both stators have the same number of poles and are excited with power frequency, thus establishing transaction of power through both stator windings independently and via rotor. In addition they establish flux coupling between both stators enhancing transient characteristics and efficiency $[6,8,9]$. A narrow speed operation without multi-gear systems remains the only limiting factor of DSIG [8]. The demerit is offset as the power density is high in such machines and rotor is cheaper with normal stator construction. The reliability of power generation is also increased as now two three phase sets deliver power to the connected three phase loads $[6,9,10]$. Normally 
the DSIG has been proposed with both symmetrical and asymmetrical winding structures for isolated application and with different kinds of load. Therefore, a need to critically evaluate the performance of both kinds of generators under real life conditions emerges.

DSIGs in case of low wind speed can act as two winding transformers to transect power between two stator windings connecting two power circuits and in case of adequate wind speed, generate power from wind and supply to the two networks connected across the two windings, thereby reducing the effective loading on either or both feeders. An assembly / cluster of such small rated DSIGs connected in parallel may support additional benefits. In this paper, the performance of DSIGs with symmetrical and asymmetrical stator winding coupled with weak grid is evaluated on the basis of voltage regulation and LVRT capability which in turn is based on establishment of air gap flux. Since the saturation of flux poses an impediment in operation of IGs, a careful study of flux in air gap is also carried out. The connected load is perturbed intentionally to observe and compare the performance of the mentioned above two types of DSIGs with respect to direct and quadrature axis flux and terminal voltage. The fault ride through capability is also evaluated by creating a LG fault. The stability during fault and the voltage recovery performance is also compared. The simulated results under MATLAB environment are presented and evaluated for different operating conditions.

\section{SYSTEM CONFIGURATION}

In the proposed scheme a $5 \mathrm{HP}, 4$ Pole DSIG is connected directly to two different sets of three phase distribution feeders (DFs), DF 1 and DF 2 with appropriate relative phase shifts in respective set of phases. Figure 1 shows the test bench configuration used for comparative evaluation of symmetrical and asymmetrical DSIG. According to the connected IG appropriate relative phase shifts in respective set of phases is provide on the DF1. Reactive power demand of DSIG is supported by the distribution feeders to which the winding sets are connected respectively. Two separate capacitor banks $(\mathrm{C}=9$ $\mu \mathrm{F})$ are provided at each stator winding terminal to partially support reactive power requirement and filter the currents for range of current harmonics and restraining them to enter the terminals of DSIG. Different types of passive loads are connected to both set of three phase windings of DSIG to study the effect of load dynamics seen by the proposed configurations.

\section{MATHEMATICAL MODELING}

Two balanced three phase windings displaced to each other by $30^{\circ}$ (asymmetrical) and $60^{\circ}$ (symmetrical) are considered for modeling of DSIG under the following assumptions: Air-gap is uniform and the windings are sinusoidally distributed around the air-gap and the magnetic saturation and core-losses are neglected. The voltage equations are written in $\mathrm{d}-\mathrm{q}$ axis for DSIG in synchronous reference frame as:

$$
V_{q s 1}=R_{s 1} \cdot I_{q s 1}+p\left(\chi_{q s 1}\right)+\omega\left(\chi_{d s 1}\right)
$$

$$
\begin{aligned}
& V_{d s 1}=R_{s 1} \cdot I_{d s 1}+p\left(\chi_{d s 1}\right)+\omega\left(\chi_{q s 1}\right) \\
& V_{q s 2}=R_{s 2} \cdot I_{q s 2}+p\left(\chi_{q s 2}\right)+\omega\left(\chi_{d s 2}\right)
\end{aligned}
$$

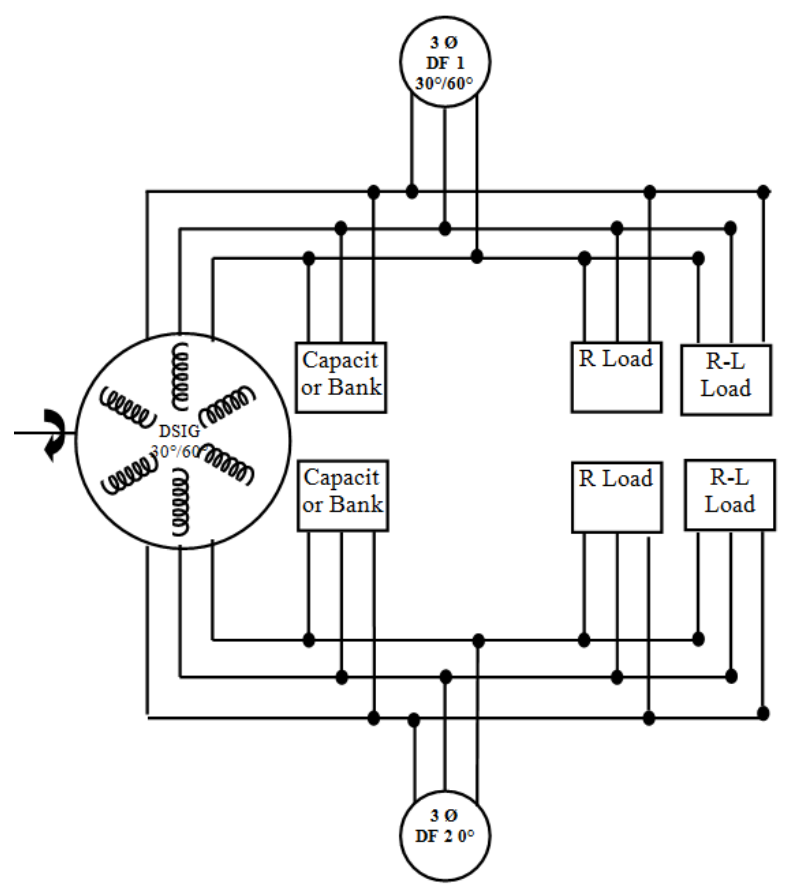

Fig. 1. Block diagram of the considered system.

$$
\begin{aligned}
& V_{d s 2}=R_{s 2} \cdot I_{d s 2}+p\left(\chi_{d s 2}\right)+\omega\left(\chi_{q s 2}\right) \\
& V_{q r}=R_{r} \cdot I_{q r}+p\left(\chi_{q r}\right)+\left(\omega-w_{r}\right)\left(\chi_{d r}\right) \\
& V_{d r}=R_{r} \cdot I_{d r}+p\left(\chi_{d r}\right)-\left(\omega-w_{r}\right)\left(\chi_{q r}\right) \\
& \chi_{q s 1}=L_{l s} i_{q s 1}+L_{l m}\left(i_{q s 1}+i_{q s 2}\right)+L_{m}\left(i_{q s}+i_{q s 2}+i_{q r}\right) \\
& \chi_{d s 1}=L_{l s} i_{d s 1}+L_{l m}\left(i_{d s 1}+i_{d s 2}\right)+L_{m}\left(i_{d s 1}+i_{d s 2}+i_{d r}\right) \\
& \chi_{q s 2}=L_{l s} i_{q s 2}+L_{l m}\left(i_{q s 1}+i_{q s 2}\right)+L_{m}\left(i_{q s 1}+i_{q s 2}+i_{q r}\right) \\
& \chi_{d s 2}=L_{l s} i_{d s 2}+L_{l m}\left(i_{d s 1}+i_{d s 2}\right)+L_{m}\left(i_{d s 1}+i_{d s 2}+i_{d r}\right) \\
& \chi_{q r}=L_{l r} \cdot i_{q r}+L_{m}\left(i_{q s 1}+i_{q s 2}+i_{q r}\right) \\
& \chi_{d r}=L_{l r} \cdot i_{d r}+L_{m}\left(i_{d s 1}+i_{d s 2}+i_{d r}\right)
\end{aligned}
$$

Since the model is designed for squirrel cage induction generator, therefore, $V_{q r}=0$ and $V_{d r}=0$. Thus the real and reactive power flowing in the two circuits can be represented as in equations $(7 \mathrm{a}-\mathrm{d})$.

$$
\begin{aligned}
& p_{1}=v_{d s 1} \cdot i_{d s 1}+v_{q s 1} \cdot i_{q s 1} \\
& q_{1}=v_{d s 1} \cdot i_{q s 1}-v_{q s 1} \cdot i_{d s 1} \\
& p_{2}=v_{d s 2} \cdot i_{d s 2}+v_{q s 2} \cdot i_{q s 2} \\
& q_{2}=v_{d s 2} \cdot i_{q s 2}-v_{q s 2} \cdot i_{d s 2}
\end{aligned}
$$

Where $\chi_{\mathrm{qs} 1}, \chi_{\mathrm{qs} 2}$ are stator q-axis flux linkage components, $\chi_{\mathrm{ds} 1}, \chi_{\mathrm{ds} 2}$ are stator $\mathrm{d}$-axis flux linkage components, $\chi_{\mathrm{qr}}^{\prime}, \chi_{\mathrm{dr}}^{\prime}$ are rotor $\mathrm{q}$-axis and $\mathrm{d}$-axis flux linkage components, $\mathrm{i}_{\mathrm{qs} 1}, \mathrm{i}_{\mathrm{qs} 2}$ are 
stator $\mathrm{q}$-axis current components, $\mathrm{i}_{\mathrm{ds} 1}, \mathrm{i}_{\mathrm{ds} 2}$ are stator d-axis current components, $\mathrm{i}_{\mathrm{qr}}^{\prime}, \mathrm{i}_{\mathrm{dr}}^{\prime}$ are rotor $\mathrm{q}$-axis and d-axis current components, $\mathrm{L}_{\mathrm{ls}}$ is stator leakage inductance, $\mathrm{L}_{\mathrm{m}}$ is air gap inductance, $\mathrm{L}_{\mathrm{lm}}$ is stator mutual leakage inductance, $\mathrm{L}_{\mathrm{lr}}$ is rotor leakage inductance, $\mathrm{p}$ is $(\mathrm{d} / \mathrm{dt}), \omega$ and $\omega_{\mathrm{r}}$ are synchronous flux and rotor speed, $R_{s}$ and $R_{r}$ are stator and rotor resistances, $v_{\mathrm{qs}}$, $\mathrm{v}_{\mathrm{ds} 1}, \mathrm{v}_{\mathrm{qs} 2}, \mathrm{v}_{\mathrm{ds} 2}, \mathrm{v}_{\mathrm{qr}}^{\prime}$ and $\mathrm{v}_{\mathrm{dr}}^{\prime}$ are the stator and rotor $\mathrm{q}$-axis and $\mathrm{d}-$ axis voltages respectively. The equivalent circuit of DSIG generator in $d-q$ reference frame is shown in Figure 2(a) and 2(b) respectively. The developed modeling equations do not differentiate between the symmetrical and asymmetrical machines since the instantaneous parameters represent the waveforms, therefore more clarity on the subject would be visible through its depiction on phasor diagrams.

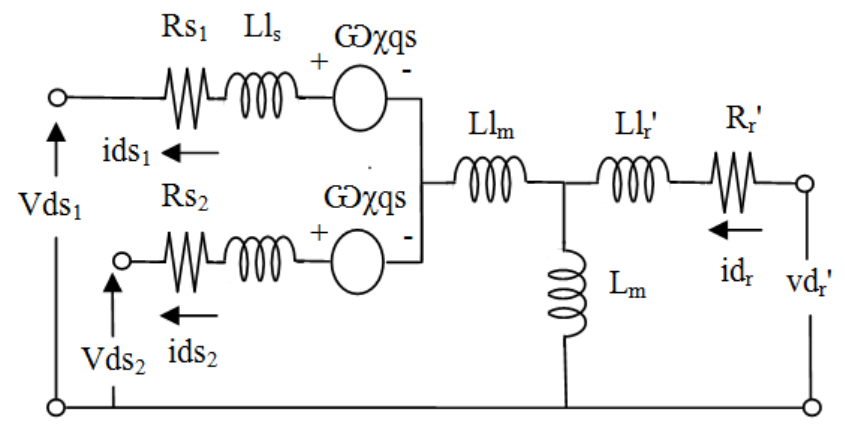

(a)

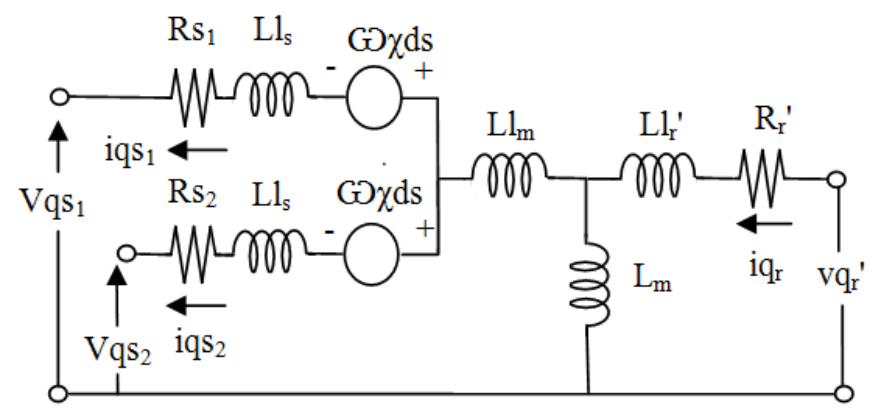

(b)

Fig. 2. (a) Equivalent circuit of DSIG in d-axis (b) Equivalent circuit of DSIG in q-axis

\section{COMPARATIVE PHASOR BASED ANALYSIS}

It is important to analyze both types of DSIG's from the flux distribution point of view, which can be depicted separately by analysing the effect of loading on both leading and lagging windings and their contribution on direct and quadrature axes. The differences in operating characteristics are visible and strongly influence the results shown with both DSIGs. Figure 3 shows the phasor diagram showing leading and lagging winding currents of asymmetrical and symmetrical DSIG in terms of direct axis and quadrature axis. To study the effect of leading and lagging winding current on one another the projection of one current is taken on the other current and the resultant leading and lagging current phasor is drawn. For simplification and ease of understanding the resultant phasors for both DSIGs are calculated taking leading winding as a reference. The projections of a current phasor are represented by dotted lines with the same color to that of the current phasor. Superscripts ' $*$ ' and ' $* *$ ' are used to represent the direct axis and quadrature axis projections of lagging winding on leading winding axis and superscripts " $\#$, and "\#\#, are used to represent the direct axis and quadrature axis projections of leading winding on lagging winding axis. Thick solid hashed lines represent the net leading and lagging winding current after incorporating the projections of their respective direct and quadrature current components. Figures 3(a), 3(d) for instance represent the direct and quadrature components for current phasor of leading and lagging winding asymmetrical DSIG. Figure 3(b) represents the projection of lagging winding currents upon leading winding currents of asymmetrical DSIG. Figure 3(c) represents the resultant leading winding current of asymmetrical DSIG incorporating the projections shown in Figure 3(b). Similarly Figures 3(e), 3(f) represent the projections of leading winding currents on the lagging winding currents and the resultant lagging winding currents after incorporating the projections respectively for asymmetrical DSIG. Figures 3(g-l) represent the current phasor for symmetrical DSIG for projection on leading and lagging winding currents. The quadrature and direct axis components of current phasors depicted in Figures 3(c), 3(f), 3(i) and 3(1) are also represented mathematically in equations (8)-(9), (11)(12), (14)-(15) and (17)-(18) respectively. The net current phasors are given by (10), (13), (16) and (19).

\section{- $\quad$ For Asymmetrical DSIG} side:

For projection of lagging winding side to leading winding

$$
\begin{aligned}
& I_{1 q, A S}=0+j 2.37 \\
& I_{1 d, A S}=-1.37+j 0 \\
& I_{1 N E T, A S}=-1.37+j 2.37
\end{aligned}
$$
side:

For projection of leading winding side to lagging winding

$$
\begin{aligned}
& I_{2 q, A S}=0.69+j 1.19 \\
& I_{2 d, A S}=-2.05+j 1.18 \\
& I_{2 N E T, A S}=-1.36+j 2.37
\end{aligned}
$$

- For Symmetrical DSIG

For projection of lagging winding side to leading winding side:

$$
\begin{aligned}
& I_{1 q, S}=0+j 2.37 \\
& I_{1 d, S}=-0.63+j 0 \\
& I_{1 N E T, S}=-0.63+j 2.37
\end{aligned}
$$

For projection of leading winding side to lagging winding side:

$$
\begin{aligned}
& I_{2 q, S}=0.55+j 0.31 \\
& I_{2 d, S}=-1.33+j 2.31 \\
& I_{2 N E T, S}=-0.78+j 2.62
\end{aligned}
$$


Comparing (10) with (16), when projection of lagging winding current component is added with current component of leading winding, it is observed that even for more real power generation the asymmetrical DSIG demands nearly the same reactive power demanded by the symmetrical DSIG, for lesser active power generation. The same is evident from comparison of Figures 3(c) and 3(i) and collaborated by comparing (13) with (19).

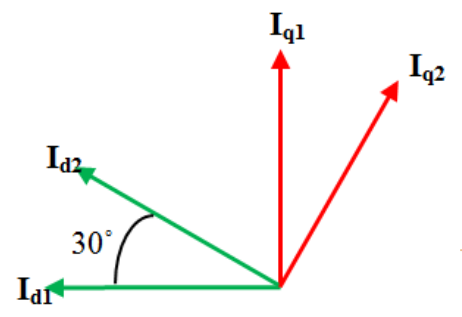

(a) Phasor of Id and Iq for both leading (I1) and lagging (I2)winding currents

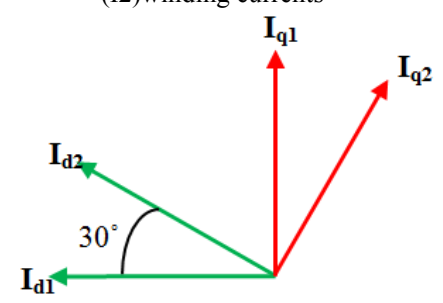

(d) Phasor of Id and Iq for both leading (I1) and lagging (I2)winding currents

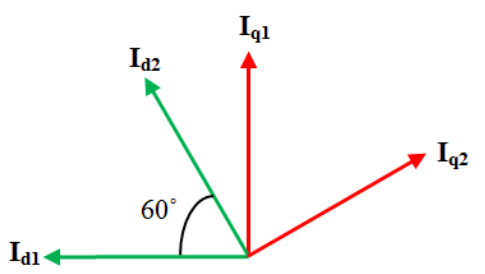

(g) Phasor of Id and Iq for both leading (I1) and lagging (I2)winding currents

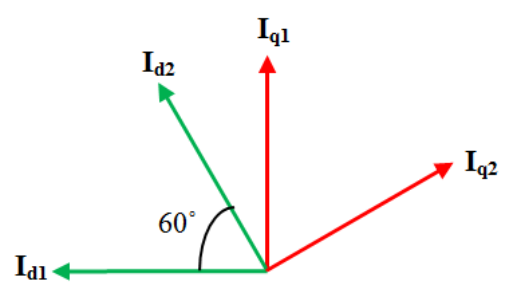

(j) Phasor of Id and Iq for both leading (I1) and lagging (I2)winding currents

\section{Asymmetrical DSIG}

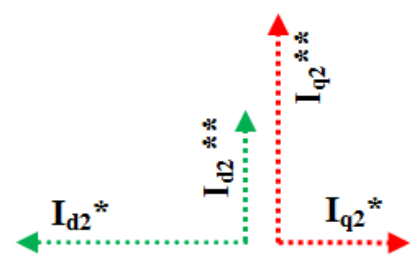

(b) Projection of Id and Iq of lagging (I2) winding current on leading winding current (I1)

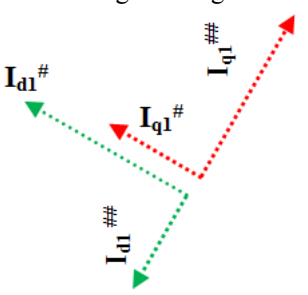

(e) Projection of Id and Iq of leading (I1) winding current on lagging winding current (I2)

\section{Symmetrical DSIG}

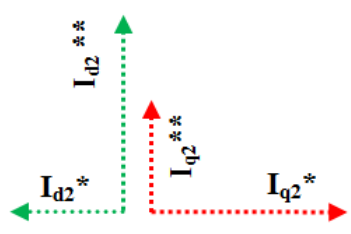

(h) Projection of Id and Iq of lagging (I2) winding current on leading winding current (I1)

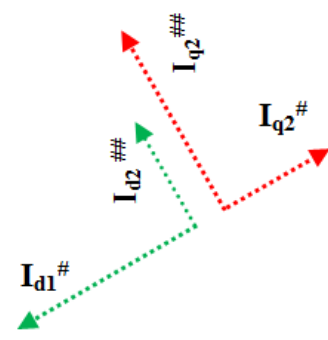

(k) Projection of Id and Iq of leading (I2) winding current on lagging winding current (I1)

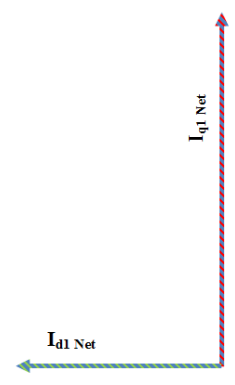

(c) Resultant Id and Iq of leading (I1) winding current

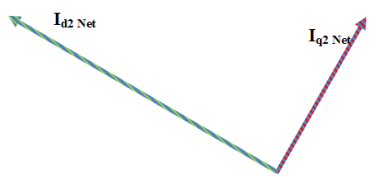

(f) Resultant Id and Iq of lagging (I2) winding current

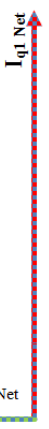

(i) Resultant Id and Iq of leading (I1) winding current

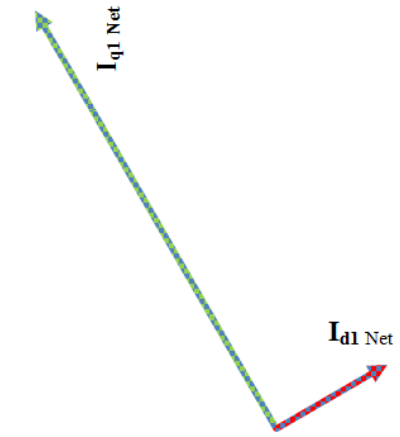

(1) Resultant Id and Iq of leading (I1) winding current

Fig. 3. DSIG phasor diagram: (a)-(f) Asymmetrical DSIG: Projection of Lagging to Leading, (g)-(l) Symmetrical DSIG: Projection of Lagging to Leading Winding 


\section{MATLAB SIMULATION}

The type of DSIG under consideration is $5 \mathrm{HP}, 4$ pole, 50 $\mathrm{Hz}, 415 \mathrm{~V}$. Leading winding side of DSIG is connected to grid with respective phase shift of $30^{\circ}$ for asymmetrical and $60^{\circ}$ for symmetrical winding type DSIG. Similarly lagging winding side of DSIG is connected to grid without any phase shift. Both the grid connections are identical except the difference in their phase for connection to leading side. Two distinct equal value three phase capacitor banks are connected to both the winding sets (leading and lagging) of DSIG to partially support the excitation and to filter out any harmonics arriving from load towards generators. Different types of passive loadings (resistive and resistive-inductive loads) are considered connected to both sides with details given in Table I.

TABLE I. RATING OF DIFFERENT LOADS

\begin{tabular}{|c|c|}
\hline Type of Load & Value of Load \\
\hline Resistive & $\mathrm{R}=180 \Omega$ \\
\hline Resistive Inductive & $\mathrm{Z}=180 \Omega(0.8 \mathrm{pf})$ \\
\hline
\end{tabular}

\section{PERFORMANCE EVALUATION}

The performance of weak grid coupled DSIGs with symmetrical and asymmetrical stator windings is evaluated comparatively on the basis of voltage regulation and operation under low voltage which in turn is based on establishment of air gap flux. Since the saturation of flux poses as an impediment in operation of IG a careful study of flux in air gap is requisite. The simulated results under MATLAB environment are evaluated for different operating conditions. The connected load is perturbed intentionally to observe and compare the performance of the afore said two types of DSIGs in respect of direct and quadrature axis flux and terminal voltage on the point of common coupling. The utilization of the core and transient characteristic is also been compared by analyzing the direct and quadrature axis flux under steady state and transient conditions during the occurrence of single phase LG fault. Perturbing loads are applied to the terminals of both winding sets of DSIG and their relative effect on their voltage profile and flux are observed and evaluated. To study the effect of cross-coupling, the IGs are loaded in three steps. Initially from $\mathrm{t}=0$ to $\mathrm{t}=0.2 \mathrm{~s}$ both DSIGs are at no-load. It may be observed from Figure 5 that equal terminal voltages of $340 \mathrm{~V}$ are present. At $\mathrm{t}=0.2 \mathrm{~s}$ when both winding sets of the DSIGs are equally loaded with $1.75 \mathrm{~kW}$ upf load on each winding set it resulted in the voltage fall from $340 \mathrm{~V}$ to $330 \mathrm{~V}$ for both symmetrical and asymmetrical DSIGs. Further at $t=0.3 \mathrm{~s}$ when the loading on leading winding side of both the IGs is increased by $750 \mathrm{~W}$ each, whereas on lagging side load is kept as it is, a fall in voltage on the leading winding side of the IGs is observed, which varied from $330 \mathrm{~V}$ to $322 \mathrm{~V}$. But as the cross coupling effect which is more prominent for the asymmetrical DSIG the voltage at the lagging winding side increases to $335 \mathrm{~V}$, whereas, in the symmetrical DSIG where the effect is not prominent the terminal voltage remain almost same at $330 \mathrm{~V}$. Again at $\mathrm{t}=0.4 \mathrm{~s}$, a load is applied at the lagging winding of both symmetrical as well as asymmetrical DSIG the additional load applied is the preceding perturbation on leading side withdrawn. The terminal voltage of lagging winding side is decreased from $331 \mathrm{~V}$ to $322 \mathrm{~V}$ for symmetrical DSIG and from $335 \mathrm{~V}$ to $328 \mathrm{~V}$ for asymmetrical DSIG. The effect of cross-coupling in asymmetrical DSIG is once again clearly visible with rise of terminal voltage on the leading winding side i.e. from $322 \mathrm{~V}$ to $335 \mathrm{~V}$. On the other hand, the terminal voltage of leading winding for symmetrical DSIG shows small effect of cross-coupling with a rise of terminal voltage (from $322 \mathrm{~V}$ to $330 \mathrm{~V})$.

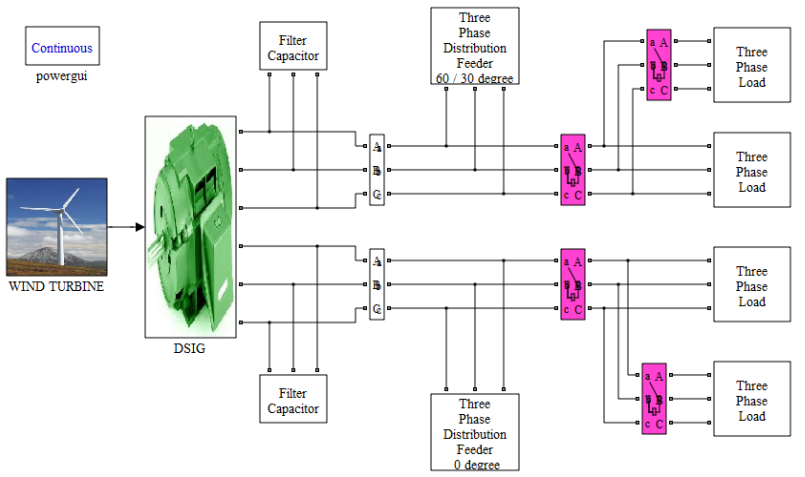

Fig. 4. MATLAB / Simulink Model of the Proposed System

Detailed comparison between symmetrical and asymmetrical DSIG is also carried out by analysis of the flux distribution. It may be observed in Figure 6(a), that the core utilization is very well justified in asymmetrical DSIG where both direct and quadrature axis flux are nearly equal giving a circular shape of d-q flux graph. Whereas, in Figure 6(b) it is evident that the $\mathrm{d}$ axis and $\mathrm{q}$ axis flux is highly skewed in symmetrical DSIG and the fluxes are not equal, giving it an elliptical shape on the $\mathrm{d}-\mathrm{q}$ axis indicating its vulnerability to core saturation. Prior to loading the quadrature axis flux values of symmetrical DSIG ranges from -1 to 1 p.u. and -0.75 to 0.75 p.u. for asymmetrical DSIG and, the direct axis flux value ranges from -0.25 to 0.25 p.u. and 0.75 to 0.75 p.u. for symmetrical and asymmetrical DSIG respectively. It may be observed from Figure 6 that after resistive loading on lagging winding side the d-q plot of flux gets slightly compressed vertically and slightly bulges horizontally for both symmetrical and asymmetrical DSIG in the same proportion. The similar effect is observed for both IGs for the loading changes on winding side.

To examine the fault ride through capability of DSIG a line to ground fault is created for ten (10) cycles and d-q axis fluxes are plotted in Figure 7 before fault, during fault and during recovery period. Figure 7 shows the plot for direct and quadrature axis flux during pre-fault period for both symmetrical and asymmetrical DSIG. It may be observed from Figure 7 that asymmetrical DSIG shows better stability during fault, which helps during recovery period after fault is removed, compared to symmetrical DSIG. During pre fault conditions the direct and quadrature axis flux values for symmetrical DSIG are observed as (-0.35 to 0.35$)$ and ( -0.95 to $0.95)$ respectively, whereas, for asymmetrical DSIG they vary 
between (-0.8 to 0.8$)$ and (-0.6 to 0.6$)$ respectively. Quadrature flux of symmetrical DSIG shows more drastic changes when compared with asymmetrical DSIG, whereas, the direct axis flux show relatively lesser decrementing tendency than for the quadrature axis. The symmetrical DSIG witness a decrease from 0.35 to 0.15 p.u. ( $55 \%$ drop) and asymmetrical DSIG witness the decrease from 0.8 to 0.45 p.u. ( $43 \%$ drop) in the direct axis flux, whereas, quadrature axis see a decrease from 0.9 to 0.75 p.u. ( $15 \%$ drop) for symmetrical DSIG and almost no change in quadrature axis flux for asymmetrical DSIG.
During recovery period also the tendency of asymmetrical DSIG to get back to normal position is fast as the growth in quadrature axis flux is more rapid than in case of symmetrical DSIG. The symmetrical DSIG shows a slower response compared to asymmetrical DSIG during recovery. The results of the comprehensive analysis are presented in Table II, which depicts the relative merits of asymmetrical DSIG over the symmetrical DSIG for different operating conditions including LVRT and fault conditions.

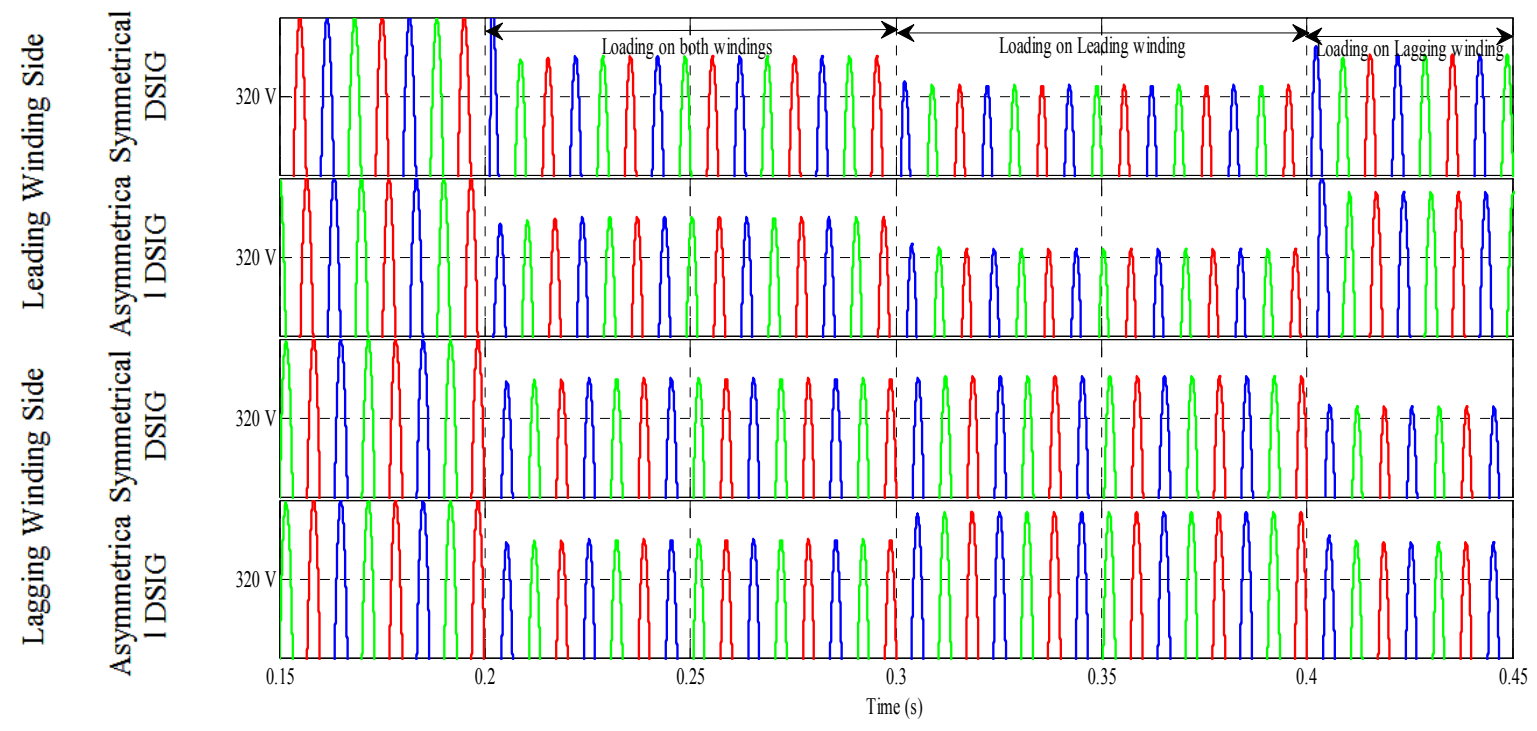

Fig. 5. Terminal Voltages of Symmetrical and Asymmetrical DSIG

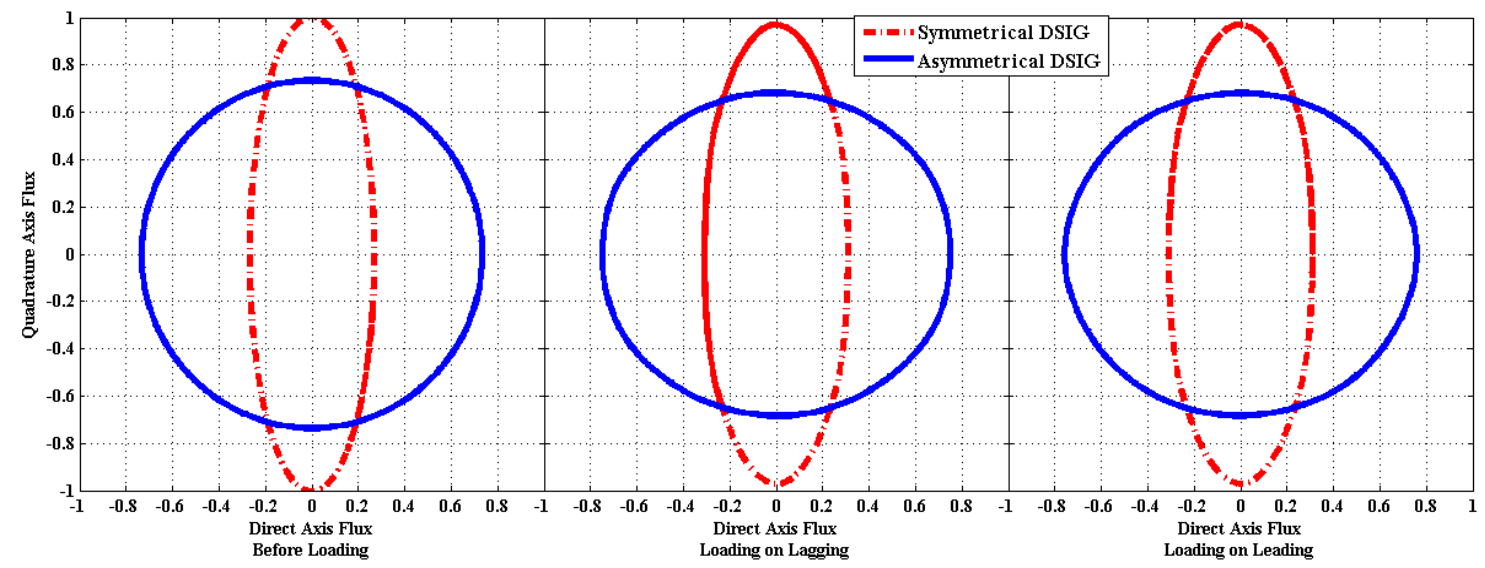

Fig. 6. Effect of Loading on Air Gap Flux

TABLE II. COMPARATIVE CHART OF SYMMETRICAL AND ASYMMETRICAL DSIG UNDER DIFFERENT LOADING AND FAULT CONDITIONS

\begin{tabular}{|c|c|c|c|c|}
\hline Property & Voltage (Cross-Coupling) & Current THD & $\begin{array}{c}\text { Fault Ride } \\
\text { Through }\end{array}$ & d-q Flux Graph \\
\hline Symmetrical DSIG & Less pronounced & Higher & Poor & Asymmetrical \\
\hline Asymmetrical DSIG & More pronounced & Lower & Good & Symmetrical \\
\hline
\end{tabular}




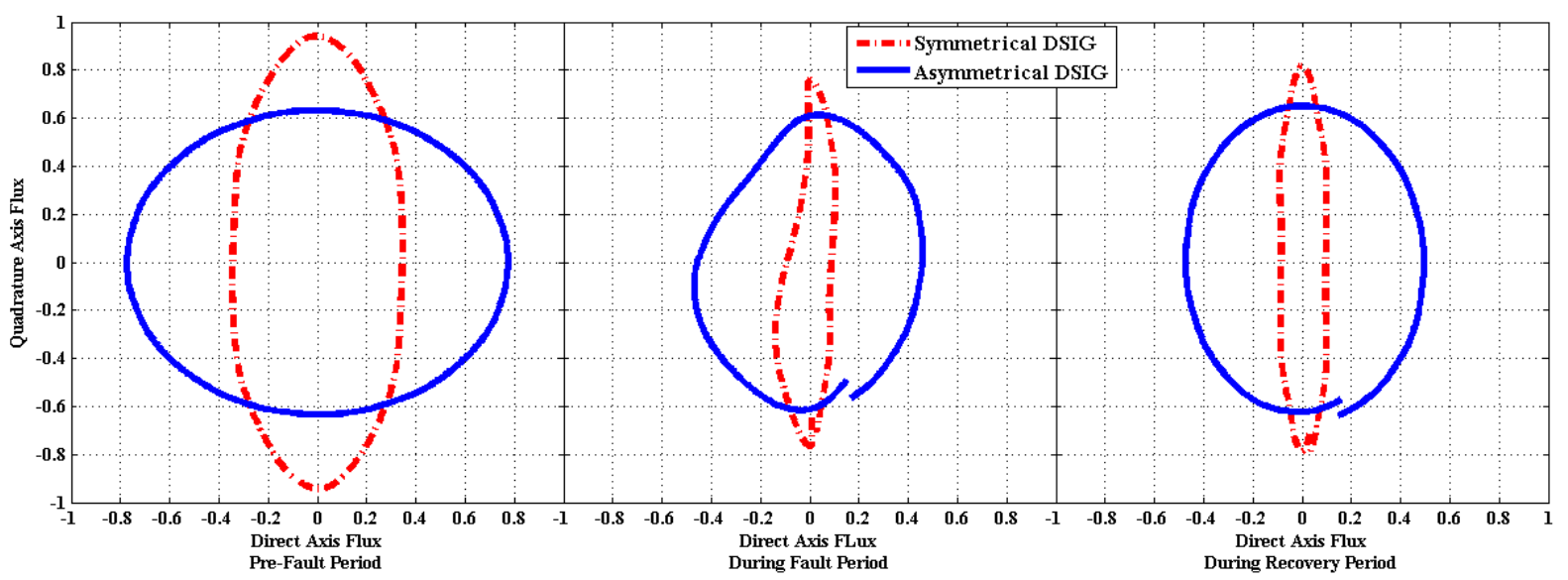

Fig. 7. Effect of LG Fault(10Cycles) on Air Gap Flux

\section{CONCLUSION}

In this paper, we presented a comparative evaluation of operating characteristics of symmetrical and asymmetrical DSIG. The mathematical model of both DSIGs has been developed for comparative analysis. A phasor analysis was also drawn in terms of winding currents for symmetrical and asymmetrical type DSIGs. The comparative performance of the IGs was observed on the basis of demonstrated results for perturbing loads through direct and quadrature axis flux of the air gap and dynamics during recovery of voltage. Demonstrated result also revealed the asymmetrical generator harvests, the advantage of cross coupling which enables the regulation of voltage by magnetizing the effect of reduction in flux. Results demonstrated the superiority of asymmetrical DSIG for wind energy applications. Practically provision of a phase shift of $30^{\circ}$ is easily attained with the help of star delta transformer thus adds to the merits of asymmetrical generator over the symmetrical one.

\section{REFERENCES}

[1] H. Polinder, F. F. A. Van der Pijl, G.-J. de Vilder, P. J. Tavner, "Comparison of Direct-Drive and Geared Generator Concepts for Wind Turbines", IEEE Transactions on Energy Conversion, Vol. 21, No. 3, pp. $725-73,2006$

[2] K. Protsenko, D. Xu, "Modeling and Control of Brushless Doubly-Fed Induction Generators in Wind Energy Applications", IEEE Transactions on Power Electronics, Vol. 23, No. 3, pp. 1191-1197, 2008

[3] F. Bu, Y. Hu, W. Huang, S. Zhuang, K. Shi, "Control Strategy and Dynamic Performance of Dual Stator-Winding Induction Generator
Variable Frequency AC Generating System With Inductive and Capacitive Loads", IEEE Transactions on Power Electronics, Vol. 29, No. 4, pp. 1681- 1692, 2014

[4] T. Long, S. Shao, P. Malliband, E. Abdi, R. A. McMahon, "Crowbarless Fault Ride-Through of the Brushless Doubly Fed Induction Generator in a Wind Turbine Under Symmetrical Voltage Dips", IEEE Transactions on Industrial Electronics, Vol. 60, No. 7, pp. 2833-2841, 2013

[5] S. Tohidi, H. Oraee, M. R. Zolghadri, S. Shao, P. Tavner, "Analysis and Enhancement of Low-Voltage Ride-Through Capability of Brushless Doubly Fed Induction Generator", IEEE Transactions on Industrial Electronics, Vol. 60, No. 3, pp. 1146-1155, 2013

[6] R. Boraci, M. Babescu, N. Budisan, A. R. Boraci, "Mathematical Model of The Two Orthogonal Three-Phase Windings Stator Generator", 5th International Symposium on Applied Computational Intelligence and Informatics, Romania, May 28- 29, 2009

[7] S. Shao, T. Long, E. Abdi, Richard A. McMahon, "Dynamic Control of the Brushless Doubly Fed Induction Generator Under Unbalanced Operation”, IEEE Transactions on Industrial Electronics, Vol. 60, No. 6, pp. 2465-2476, 2013

[8] N. Budisan, O. Prostean, R. Boraci, I. Szeidert, V. Muller, "The Dual Induction Generator for Renewable Energy Conversion Systems. Experimental Results, Problems and Solutions", IEEE International Joint Conferences on Computational Cybernetics and Technical Informatics, Romania, May 27-29, 2010

[9] R. Singh, V. Verma, "Dual Stator Induction Generator for Rural Electrification", International Journal of Applied Engineering Research, Vol. 12, No. 16, pp. 5865-587, 2017

[10] F. Bu, L. Zhu, W. Huang, H. Xu, H. Liu, Y. Gao, "Control strategy of AC\&DC hybrid generating system based on dual stator-winding induction generator for micro-grid application", IEEE Transportation Electrification Conference and Expo, pp. 013-017, 2016 